\title{
Desempenho de novilhas em pastagem de Brachiaria decumbens após período de suplementação
}

\author{
Luiz Fernando Mesquita Cavalcanti Filho(1), Mércia Virginia Ferreira dos Santos ${ }^{(2)}$, Marcelo de Andrade Ferreira ${ }^{(2)}$, \\ Mário de Andrade Lira(2), Iderval Farias ${ }^{(3)}$, Rinaldo Luiz Caraciolo Ferreira ${ }^{(4)}$ e Jorge Eduardo Cavalcanti Lucena ${ }^{(2)}$ \\ (1)Av. Frederico Lundgreen, 329, Rio Doce, CEP 53140-000 Olinda, PE (2)Universidade Federal Rural de Pernambuco (UFRPE), Dep. de \\ Zootecnia, Rua Dom Manoel de Medeiros, s/no, Dois Irmãos, CEP 52171-900 Recife, PE. E-mail: mercia@ufrpe.br, \\ ferreira@ufrpe.br, mlira@hotlink.com.br, jlucena@yahoo.br (3)Empresa Pernambucana de Pesquisa Agropecuária, Av. San Martin, 1356, \\ Bonji, CEP 50630-000 Recife, PE. E-mail: iderval@ipa.br (4)UFRPE, Dep. de Ciência Florestal. E-mail: rinaldof@ufrpe.br
}

Resumo - O objetivo deste trabalho foi avaliar o desempenho de novilhas em pastagem de Brachiaria decumbens Stapf. após período de suplementação, na Zona da Mata de Pernambuco. A suplementação protéica foi baseada em farelo de algodão e a protéica/energética foi uma mistura de 50\% de farelo de algodão e $50 \%$ de milho triturado. Foram utilizadas 18 novilhas 5/8 Holandês/Zebu, com peso vivo médio de 267,33 kg e idade média de 20 meses. As suplementações anteriores não influenciaram o peso vivo inicial, peso vivo final, ganho de peso médio diário e a taxa de prenhez das novilhas, que apresentaram, respectivamente, valores médios de 267,33 kg, $335,33 \mathrm{~kg}, 345,81 \mathrm{~g} \mathrm{e} 33,22 \%$. O consumo de forragem das novilhas foi afetado pela suplementação e os maiores níveis de ingestão foram obtidos no tratamento sem suplementação e com suplementação protéica/energética, decrescendo ao longo do período experimental pós-suplementação.

Termos para indexação: consumo de nutrientes, ganho de peso, taxa de prenhez.

\section{Heifers forage intake and performance on Brachiaria decumbens after supplementation}

\begin{abstract}
The objective of this trial was to characterize heifers performance after a supplementation period at the coastal region of Pernambuco State, Brazil. The protein source to the proteic supplementation was cotton seed meal and the proteic/energetic supplementation was a mix of 50\% cotton seed meal and 50\% ground corn. Eighteen 5/8 Holstein/Zebu heifers were used, with an average liveweight of $267.33 \mathrm{~kg}$ and averaging 20 months of age. Previous supplementation did not influence initial liveweight, final liveweight, average daily gain and pregnancy rate of the evaluated heifers, which presented average values of $267.33 \mathrm{~kg}, 335.33 \mathrm{~kg}, 345.81 \mathrm{~g}$ and $33.22 \%$, respectively. Dry matter intake was influenced by the previous supplementation and the higher intake level occurred for the control treatment as well as for the energetic/proteic supplementation treatment, decreasing along grazing periods.
\end{abstract}

Index terms: liveweight, nutrient intake, pregnancy rate.

\section{Introdução}

A Zona da Mata de Pernambuco possui aproximadamente 1.200.000 ha, e o cultivo predominante é a canade-açúcar (Dubeux Júnior et al., 1997). No entanto, a topografia acidentada reduz as áreas próprias para o cultivo de cana-de-açúcar a cerca de 200.000 ha, restando aproximadamente 1.000.000 ha para diversificação. Entre as opções de diversificação, destaca-se a pecuária. A proximidade do mercado consumidor e fatores como pluviosidade, temperatura e luminosidade são favoráveis ao cultivo de plantas forrageiras, apesar da baixa fertilidade natural do solo, elementos fundamentais ao desenvolvimento da atividade pecuária. Além disso, as plantas forrageiras propiciam uma cobertura vegetal e a proteção dos solos de topografia acidentada (Vale, 1995).

A precipitação pluvial média da Zona da Mata de Pernambuco varia entre 1.000 e $2.500 \mathrm{~mm}$, com distribuição modal de chuvas durante o ano, ocorrendo seis meses de período chuvoso e seis de período seco. Apesar da pluviosidade satisfatória para a manutenção de gramíneas com elevado potencial forrageiro, durante a estação seca, a disponibilidade e a qualidade da forra- 
gem diminuem bastante, prejudicando principalmente animais em crescimento, cuja exigência protéica é elevada. Tal fato tem sido responsável pela redução no crescimento de novilhas, futuras matrizes e produtoras de leite. Nesse período, a alimentação é deficiente tanto em quantidade quanto em qualidade da forragem, o que provoca a redução do crescimento e a perda de peso levando ao retardamento da primeira cobertura das novilhas, a qual deveria ocorrer em torno de 24 meses de idade ou $300 \mathrm{~kg}$ de peso vivo (Campos \& Liziere, 1995).

A suplementação alimentar tem sido uma alternativa para atenuar os efeitos da seca sobre o desenvolvimento dos animais. Entretanto, os elevados preços das rações e concentrados prejudicam a aplicação dessa técnica em bezerros e novilhas. Além disso, discute-se se a suplementação na seca deve ser apenas para a mantença animal, podendo ocorrer perda de peso nesta época e ganho de peso mais rápido na estação das águas. $\mathrm{O}$ ganho compensatório pode ser considerado como uma taxa de crescimento acima do normal, observado após um período de restrição nutricional, no qual o peso vivo dos animais aumenta ligeiramente, é mantido ou é reduzido (Almeida et al., 2001).

Dubeux Júnior et al. (1997), trabalhando com novilhas 5/8 Holandês/Zebu em pastagem de $B$. decumbens, em Itambé, PE, observaram que em dois períodos críticos do ano, houve perda de peso dos animais. No entanto, essa perda foi compensada após o início do período chuvoso, quando ocorreu ganho compensatório de aproximadamente $1.164 \mathrm{~g}$ cabeça ${ }^{-1}$ dia $^{-1}$ no período de abril a maio de 1993. Este ganho compensatório, segundo os autores, pode ter sido causado pelo aumento da disponibilidade de forragem verde, aliado ao aumento nos teores de proteína bruta do pasto. Desta forma, evidencia-se a necessidade de estudos que identifiquem os efeitos da suplementação no desenvolvimento posterior dos animais.

O objetivo deste trabalho foi determinar o desempenho de novilhas em pastagem de $B$. decumbens, submetidas à lotação contínua após período de suplementação energética e protéica, na Zona da Mata de Pernambuco.

\section{Material e Métodos}

O experimento foi realizado na Estação Experimental da Empresa Pernambucana de Pesquisa Agropecuária - IPA, em Itambé, PE, numa área de pastagem de 7,7 ha formada predominantemente por capim-braquiária (Brachiaria decumbens Stapf.). Este município localiza-se na microrregião fisiográfica da Zona da Mata Norte do Estado de Pernambuco, com latitude $7^{\circ} 25^{\prime} 0^{\prime \prime} \mathrm{S}$; longitude $35^{\circ} 6^{\prime} \mathrm{O}^{\prime \prime} \mathrm{W}$ e altitude de $190 \mathrm{~m}$. O tipo climático é subúmido megatérmico, segundo a classificação de Thorthwaite. O total de chuvas durante o período de maio a novembro de 2001 foi de $559,6 \mathrm{~mm}$, caracterizado por uma distribuição temporal irregular. De acordo com Jacomine et al. (1972), os solos dessa região são classificados como Podzólico VermelhoAmarelo equivalente distrófico com A proeminente, textura argilosa, fase floresta subcaducifólia e relevo ondulado.

O delineamento experimental utilizado foi em blocos casualizados com três tratamentos e seis repetições, e o peso inicial dos animais foi o critério adotado para formação dos blocos. Foram aplicados os tratamentos sem suplementação, suplementação protéica e suplementação protéica/energética. A suplementação protéica foi baseada em farelo de algodão e a suplementação protéica/ energética foi realizada pela mistura de $50 \%$ de farelo de algodão e $50 \%$ de milho triturado. Os suplementos foram fornecidos na proporção de $0,37 \%$ do peso vivo $(\mathrm{PV})$, sempre às 8 horas.

Foram utilizadas 18 novilhas 5/8 Holandês/Zebu com média de 20 meses de idade e 267,33 kg de PV no início do experimento. Os animais foram suplementados de 9 de março a 3 de maio de 2001 e o efeito dessa suplementação foi avaliado durante os 287 dias seguintes, de 11 de maio de 2001 a 21 de fevereiro de 2002. Durante o período experimental, os animais utilizaram a pastagem de $B$. decumbens continuamente, tendo acesso a sal mineralizado e água à vontade.

O consumo de matéria seca foi estimado em seis períodos, junho, julho, agosto, setembro, outubro e novembro de 2001, utilizando o óxido crômico como marcador externo para estimar a produção de fezes. O óxido crômico foi aplicado durante 15 dias consecutivos em uma única dose diária, entre 8 e 10 horas. A coleta de fezes foi realizada no 10 e e 15o dias de dosificação às 8 e 15 horas, respectivamente. Foram coletados aproximadamente $150 \mathrm{~g}$ de fezes diretamente no reto dos animais. A análise do teor de óxido crômico foi realizada em espectrofotômetro de absorção atômica. Conhecendo-se a estimativa da produção de matéria seca fecal de cada animal e a indigestibilidade da matéria seca, o consumo voluntário da forragem pelas novilhas foi calculado segundo Detmann et al. (2001) e Lima et al. (2001). 
O peso vivo dos animais foi determinado no início do período experimental, a cada 28 dias e no final do experimento. As novilhas entraram em estação de monta de 1ㅇ de setembro a 23 de novembro de 2001 e, em 21 de fevereiro de 2002, foram submetidas ao exame ginecológico, via palpação retal, para realização do diagnóstico de gestação e cálculo da taxa de prenhez.

Os dados foram avaliados por meio de análise de variância com desdobramento da interação, quando significativa. $\mathrm{O}$ teste de comparação de médias utilizado foi o de Tukey a $5 \%$ de probabilidade. Os dados de prenhez dos animais foram analisados pelo teste do quiquadrado, utilizando tabela de contingência $3 \times 2$ do teste de Mantel-Haenszel (Ott, 1993).

\section{Resultados e Discussão}

Foram observados efeitos significativos para consumo de forragem entre os tratamentos utilizados e os meses de avaliação, mas a interação entre esses fatores não foi significativa (Tabela 1). Os animais do tratamento testemunha apresentaram maior nível de consumo de MS, PB, FDN e FDA, do que aqueles que receberam suplementação protéica. Os animais que receberam suplementação protéica/energética apresentaram consumos semelhantes aos animais sem suplementação e aos com suplementação protéica.

Segundo Valadares et al. (1997) e Pascoal et al. (2000), o consumo voluntário normalmente se eleva com o aumento do peso vivo, por causa do aumento na capacidade de consumo, provocado pelo crescimento dos animais e desenvolvimento do trato digestivo. Neste tra- balho ocorreu efeito contrário, verificando-se leve redução do consumo de PB e FDA ao longo dos meses de amostragem (Tabela 1). Com o avanço no ciclo fenológico, as plantas diminuem sensivelmente seus teores de proteína e aumentam os de FDN, provocando diminuição na digestibilidade (Van Soest, 1994) e, conseqüentemente, menor consumo (Mertens, 1994). Outros fatores como a redução na pluviosidade, altura do pasto, massa de forragem e disponibilidade de folhas em relação ao caule e material senescente (Cavalcanti Filho, 2003), podem ter influenciado a redução do consumo de nutrientes ao longo dos períodos de amostragens.

O consumo médio de matéria seca registrado neste experimento $(2,24 \% \mathrm{PV})$ foi semelhante ao observado por Kabeya et al. (2002) e inferior ao obtido por Detmann et al. (2001). Esses autores trabalharam com novilhos pastejando B. decumbens Stapf., entretanto devem ser consideradas as diferenças existentes entre esses experimentos, como estado fisiológico do animal, PV, raça, sexo, e, principalmente, condições experimentais em que os resultados foram obtidos.

Os fatores que influenciam o consumo e os mecanismos que o regulam são vários e não são completamente conhecidos (National Research Council, 1996). O valor nutritivo da forragem disponível exerce influência na quantidade de forragem consumida pelos ruminantes. Sabe-se que as deficiências de nutrientes específicos podem limitar o consumo (Minson, 1990). Como os animais foram suplementados com sal mineral à vontade, pode-se admitir que o consumo não foi limitado por macro e micronutrientes. Da mesma forma, o conteúdo

Tabela 1. Consumo médio diário de matéria seca (MS), proteína bruta (PB), fibra em detergente neutro (FDN) e fibra em detergente ácido (FDA) de novilhas em pastagem de Brachiaria decumbens, após período de suplementação ${ }^{(1)}$.

\begin{tabular}{|c|c|c|c|c|}
\hline Tratamento & MS & $\mathrm{PB}$ & FDN & FDA \\
\hline Sem suplementação & $2,35 \mathrm{a}$ & $2,66 \mathrm{a}$ & $1,60 \mathrm{a}$ & $0,95 \mathrm{a}$ \\
\hline Suplementação protéica/energética & $2,30 \mathrm{ab}$ & $2,55 \mathrm{ab}$ & $1,57 \mathrm{ab}$ & $0,93 \mathrm{ab}$ \\
\hline Suplementação protéica & $2,06 \mathrm{~b}$ & $2,25 \mathrm{~b}$ & $1,40 \mathrm{~b}$ & $0,83 \mathrm{~b}$ \\
\hline \multicolumn{5}{|l|}{ Período de pastejo } \\
\hline Junho & $2,59 \mathrm{a}$ & $3,01 \mathrm{a}$ & $1,73 \mathrm{a}$ & $1,11 \mathrm{a}$ \\
\hline Julho & $2,32 \mathrm{ab}$ & $2,34 b$ & $1,68 \mathrm{a}$ & $0,96 \mathrm{ab}$ \\
\hline Agosto & $2,07 \mathrm{~b}$ & $3,41 \mathrm{a}$ & $1,20 \mathrm{~b}$ & $0,89 \mathrm{bc}$ \\
\hline Setembro & $2,21 \mathrm{ab}$ & $2,13 b c$ & $1,65 \mathrm{a}$ & $0,90 \mathrm{bc}$ \\
\hline Outubro & $2,26 \mathrm{ab}$ & $2,38 b$ & $1,47 \mathrm{ab}$ & $0,86 \mathrm{bc}$ \\
\hline Novembro & $1,99 \mathrm{~b}$ & $1,65 \mathrm{c}$ & $1,42 \mathrm{ab}$ & $0,73 \mathrm{c}$ \\
\hline Média & 2,24 & 2,49 & 1,53 & 0,91 \\
\hline $\mathrm{CV}(\%)$ & 21,02 & 21,63 & 20,88 & 20,92 \\
\hline
\end{tabular}

${ }^{(1)}$ Médias seguidas de mesma letra, na coluna, não diferem entre si a $5 \%$ de probabilidade, pelo teste de Tukey. 
de PB inferior a 7\% pode reduzir o consumo (Van Soest, 1994). No entanto, os animais selecionaram dietas com conteúdos de PB acima deste valor crítico (Cavalcanti Filho, 2003), mesmo durante períodos de baixa precipitação, de modo que a proteína não foi o fator limitante do consumo.

Outro fator que limita o consumo é a distensão do rúmen-retículo, mecanismo de particular importância no caso de consumo de gramíneas tropicais, em consequiência dos seus altos conteúdos de FDN. Segundo Van Soest (1994), o consumo de FDN é o que melhor representa a capacidade de consumo para dietas à base de volumosos e outras rações com quantidades médias e baixas de concentrado, pois são os constituintes da parede celular que ocupam maior espaço no rúmen. Mertens (1994) sugeriu que uma maneira quantitativa de identificar quando o consumo é limitado pelo enchimento do rúmen (controle físico) verifica-se na condição de a ingestão de FDN ser maior que 1,20\% do PV. Observou-se um consumo médio de $1,53 \%$ do PV, o que provavelmente influenciou o consumo voluntário neste trabalho.

Os resultados de desempenho alcançados foram comparados com as equações de predição de ganho de peso sugeridas pelo National Research Council (1989). Observou-se que o consumo de MS e PB foi relativamente próximos, às exigências recomendadas.

Não houve efeito significativo entre os tratamentos avaliados e períodos de avaliação quanto ao PV inicial, PV final e ganho de peso médio diário (Tabela 2). Contudo, o tratamento testemunha, apesar de ter iniciado o experimento com um menor PV $(258,83 \mathrm{~kg})$, foi o tratamento que numericamente apresentou maior ganho médio diário de peso $\left(381,80 \mathrm{~g}_{\text {novilha }} \mathrm{dia}^{-1}\right)$, recuperando o peso perdido durante o período de suplementação, em relação aos suplementados anteriormente.
Segundo Almeida et al. (2001), o crescimento compensatório pode permitir completa ou parcial recuperação do ganho de peso, dependendo da persistência da taxa de ganho; também pode não ocorrer aumento na taxa de ganho e, portanto, nenhuma compensação. Hogg (1991) citou vários fatores que influenciam a recuperação do peso vivo dos animais após sofrerem restrição alimentar, como idade à época da restrição, severidade e duração da restrição, duração do período de recuperação, taxa de ganho e qualidade do alimento durante a recuperação.

Dubeux Júnior et al. (1997) atribuíram o efeito de um ganho compensatório de novilhas de aproximadamente $1.164 \mathrm{~g} \mathrm{cabeça}^{-1} \mathrm{dia}^{-1}$, alcançado no período chuvoso em relação ao período seco, ao aumento da massa de forragem e aos teores de proteína bruta do pasto. Tal fato pode justificar os resultados obtidos, em que, segundo Cavalcanti Filho (2003), foram observados alta massa de forragem ( $4.423 \mathrm{~kg} \mathrm{ha}^{-1}$ de MS ) e ótimos teores de proteína bruta $(14,2 \%)$ na dieta selecionada pelos animais durante todo o período experimental.

Segundo Poppi \& McLennan (1995), em condições tropicais, o ganho de peso satisfatório para bovinos mantidos em pastagens deve ser de no mínimo $300 \mathrm{~g} \mathrm{dia}^{-1}$. Neste experimento, o ganho foi de $345,81 \mathrm{~g} \mathrm{dia}^{-1}$, porém, mesmo em seu período de crescimento ótimo e com qualidade, as pastagens tropicais proporcionam ganhos inferiores aos das pastagens das regiões temperadas nas mesmas condições.

O ganho de peso médio diário obtido foi inferior aos observados em trabalhos anteriores conduzidos com novilhas não suplementadas em pastagem de B. decumbens, na mesma estação experimental onde Lira et al. (1995) encontraram ganho médio de $523 \mathrm{~g}$ novilha ${ }^{-1} \mathrm{dia}^{-1}$, enquanto Dubeux Júnior et al. (1997) obtiveram ganho médio de 424 g novilha ${ }^{-1}$ dia $^{-1}$. O menor ganho médio observado neste trabalho provavelmente ocorreu em

Tabela 2. Peso vivo inicial (PVI), peso vivo final (PVF), ganho de peso médio diário (GPMD) e taxa de prenhez de novilhas após período de suplementação em pastagem de Brachiaria decumbens ${ }^{(1)}$.

\begin{tabular}{|c|c|c|c|c|}
\hline Tratamento & $\begin{array}{l}\text { PVI } \\
(\mathrm{kg})\end{array}$ & $\begin{array}{l}\text { PVF } \\
(\mathrm{kg})\end{array}$ & $\begin{array}{c}\text { GPMD } \\
\left(\text { g novilha }^{-1} \text { dia }^{-1}\right)\end{array}$ & $\begin{array}{c}\text { Taxa de prenhez } \\
(\%)\end{array}$ \\
\hline Sem suplementação & $258,83 \mathrm{~A}$ & $334,33 \mathrm{~A}$ & $381,80 \mathrm{~A}$ & $16,66 \mathrm{a}$ \\
\hline Suplementação protéica & $273,83 \mathrm{~A}$ & $330,33 \mathrm{~A}$ & $288,27 \mathrm{~A}$ & $50,00 \mathrm{a}$ \\
\hline Suplementação protéica/energética & $269,33 \mathrm{~A}$ & $341,33 \mathrm{~A}$ & $367,35 \mathrm{~A}$ & $33,33 \mathrm{a}$ \\
\hline Média & 267,33 & 335,33 & 345,81 & 33,22 \\
\hline $\mathrm{CV}(\%)$ & 6,85 & 6,08 & 117,99 & 145,52 \\
\hline
\end{tabular}

(1)Médias seguidas de mesma letra maiúscula, na coluna, não diferem entre si a 5\% de probabilidade, pelo teste de Tukey; médias seguidas da mesma letra minúscula não diferem entre si a $5 \%$ de probabilidade, pelo teste do qui-quadrado. 
virtude da incidência do cio e a estação de monta ocorrida durante o período experimental.

Não foi observada diferença significativa entre os tratamentos quanto à taxa de prenhez verificada nos animais (Tabela 2). Embora as taxas de prenhez possam ser consideradas satisfatórias, o baixo peso vivo médio dos animais no início da estação de monta $(313,11 \mathrm{~kg})$ pode ter afetado os resultados. Para que sejam promovidas ao rebanho de reprodução e possam continuar seu desenvolvimento, atingindo a maturidade fisiológica em boas condições físicas e fisiológicas, recomenda-se realizar a cobertura das novilhas quando atingirem determinado peso, de acordo com o nível nutricional disponível (Paulino et al., 2001). No caso do nível nutricional razoável, recomenda-se cobri-las quando apresentarem de 300 a $350 \mathrm{~kg}$ de PV. O National Research Council (1996) recomenda cobri-las quando atingirem no mínimo $65 \%$ de seu peso adulto antes da introdução no rebanho de reprodução. Considerando que, nas raças zebuínas, o peso adulto está em torno de $500 \mathrm{~kg}$, estima-se que as novilhas deveriam apresentar em torno de $325 \mathrm{~kg}$ de PV. Campos \& Lizieire (1995) recomendam a cobertura de novilhas mestiças Holandês/Zebu, ao atingirem aproximadamente $330 \mathrm{~kg}$ de PV.

Outro fator que contribuiu com a obtenção dos índices médios de prenhez foi a idade média dos animais, sendo de 22, 26 e 26 meses nos animais submetidos aos tratamentos sem suplementação, suplementação protéica e suplementação protéica/energética, respectivamente. Andrade (1993) relata que o peso não é o fator determinante de ocorrência da puberdade; a idade também deve ser considerada. Segundo o autor, novilhas que receberam alto índice nutricional alcançam pesos considerados compatíveis com a função reprodutiva a uma idade mais precoce. No entanto, normalmente a idade as impossibilita de atingirem a puberdade.

A taxa de prenhez é apenas um dos parâmetros utilizados na avaliação do desempenho reprodutivo de fêmeas a pasto. Assim, sugere-se que experimentos posteriores consideram outros parâmetros como a taxa de manifestação de cio e escore da condição corporal.

\section{Conclusões}

1. A suplementação não influencia o peso vivo inicial, peso vivo final, ganho de peso médio diário e a taxa de prenhez das novilhas.
2. O consumo de forragem das novilhas em pastagens de Brachiaria decumbens não é afetado pela suplementação.

\section{Agradecimentos}

Ao Conselho Nacional de Desenvolvimento Científico e Tecnológico (CNPq), pela bolsa concedida ao segundo, terceiro, quarto e sexto autores.

\section{Referências}

ALMEIDA, M.I.V.; FONTES, C.A. de; ALMEIDA, F.Q. de; CAMPOS, O.F.; GUIMARÃES, R.F. Conteúdo corporal e exigências líquidas e dietéticas de macroelementos minerais (Ca, P, Mg, Na e K) de novilhos mestiços holandês-gir em ganho compensatório. Revista Brasileira de Zootecnia, v.30, p.849-851, 2001.

ANDRADE, I.F. Produtividade de gramíneas sob pastejo em cerrado do triângulo mineiro. Revista Brasileira de Zootecnia, v.22, p.679693, 1993.

CAMPOS, O.F.; LIZIERE, R.S. Novilhas: elas também merecem sua atenção. Coronel Pacheco: Embrapa-CNPGL, 1995. 18p. (Circular Técnica, 36).

CAVALCANTI FILHO, L.F.M. Caracterização de pastagem de Braquiaria decumbens Stapf. e desempenho de novilhas após período de suplementação na Zona da mata de Pernambuco. 2003. 84p. Dissertação (Mestrado) - Universidade Federal Rural de Pernambuco, Recife.

DETMANN, E.; PAULINO, M.F.; ZERVOUDAKIS, J.T.; VALADARES FILHO, S.C.; EUCLYDES, R.F.; LANA, R. de P.; QUEIROZ, D.S. de. Cromo e indicadores internos na determinação do consumo de novilhos mestiços, suplementados, a pasto. Revista Brasileira de Zootecnia, v.30, p.1600-1609, 2001.

DUBEUX JÚNIOR, J.C.B.; LIRA, M. de A.; FREITAS, E.V. de; FARIAS, I. Avaliação de pastagens de braquiárias na Zona da Mata de Pernambuco. Revista Brasileira de Zootecnia, v.26, p.659666, 1997.

HOGG, B.W. Compensatory growth in ruminants. Advances in Meat Research, v.7, p.103-134, 1991.

JACOMINE, P.K.T.; CAVALCANTE, A.C.; BURGOS, N. Levantamento exploratório - reconhecimento de solos do Estado de Pernambuco: descrição de perfis de solos e análises. Recife: DNPEA; Sudene, 1972. v.1 (Boletim Técnico, 26).

KABEYA, K.S.; PAULINO, M.F.; DETMANN, E.; VALADARES FILHO, S.C.; CECON, P.R.; QUEIROZ, D.S.; GOMES JÚNIOR, P.; PEREIRA, O.G. Suplementação de novilhos mestiços em pastejo na época de transição água-seca: desempenho produtivo, características físicas de carcaça, consumo e parâmetros ruminais. Revista Brasileira de Zootecnia, v.31, p.213-222, 2002.

LIMA, M.L.P.; BARCHIELLI, T.T.; NOGUEIRA, J.R.; RUGGIERI, A.C.; AROEIRA, L.J.M.; SALMAN, A.K.D.; SOARES, J.P.C. Estimativa do consumo voluntário do capim tanzânia 
(Panicum maximum Jacq cv. Tanzânia) por vacas em lactação sob pastejo rotacionado. Revista Brasileira de Zootecnia, v.30, p.19191924, 2001.

LIRA, M. de A.; FREITAS, E.V. de; DUBEUX JÚNIOR, J.C.B.; ZARATE, R.M.T.; ANDRADE, W.B.; FARIAS, I. Avaliação de pastagens de Brachiaria decumbens e Brachiaria humidicola, Rendle, com novilhas, na Zona da Mata de Pernambuco. Revista Brasileira de Zootecnia, v.24, p.243-251, 1995.

MERTENS, D.R. Regulation of forage intake. In: FAHEY JÚNIOR, G. (Ed.). Forage quality, evaluation, and utilization. Madison: American Society of Agronomy, 1994. p.450-493.

MINSON, D.J. Forrage in ruminant nutrition. New York: Academic Press, 1990. 483p.

NATIONAL RESEARCH COUNCIL (Washington, EUA). Nutrient requeriments of beef cattle. 6th ed. Washington, D.C., 1996. 242p.

NATIONAL RESEACH COUNCIL (Washington, EUA). Nutrient requeriments of dairy cattle. Washington, D.C., 1989. 158p.

OTT, L. Categorical data. In: OTT, R.L. (Ed.). An introduction to statistical methods and data analysis. 4th ed. Belmont, CA: Duxbury Press, 1993. p.354-418.
PASCOAL, L.L.; ELFERT, E. da C.; RESTLE, J. Nível de proteína bruta para bezerros de corte desmamados aos 66 dias de idade. Revista Brasileira de Zootecnia, v.30, p.1919-1924, 2000.

PAULINO, M.F.; DETMANN, E.; ZERVOUDAKIS, J.T. Suplementos múltiplos para recria e engorda de bovinos em pastejo. In: SIMPÓSIO DE PRODUÇÃO DE GADO DE CORTE, 2., 2001, Viçosa. Anais. Viçosa: Universidade Federal de Viçosa, 2001. p.187232.

POPPI, D.P.; McLENNAN, S.R. Protein and energy utilization by ruminants at pasture. Journal of Animal Science, v.73, p.278290, 1995.

SILVA, D.J.; QUEIROZ, A.C. Análise de alimentos: métodos químicos e biológicos. 3.ed. Viçosa: Universidade Federal de Viçosa, 2002. 235p.

VALADARES, R.F.D.; GONÇALVES, D.C.; RODRÍGUEZ, N.M.; SAMPAIO, I.B.; VALADARES FILHO, S.C.; QUEIROZ, A.C. de. Níveis de proteína em dietas de bovinos: I. Consumo e digestibilidades aparentes totais e parciais. Revista Brasileira de Zootecnia, v.26, p.1252-1258, 1997.

VALE, D.C. Reengenharia do processo produtivo da cana-deaçúcar em Pernambuco. Recife: o Autor, 1995. (Documento).

VAN SOEST, P.J. Nutritional ecology of the ruminant. 2nd ed. Ithaca: Cornell University, 1994. 476p.

Recebido em 3 de maio de 2004 e aprovado em 2 de agosto de 2004 